DOI: 10.18468/letras.2017v7n4.p439-463

\title{
A informática na educação e os alunos da terceira idade:
}

\author{
relatos do Ceja Baturité
}

\author{
Sofia Regina Paiva Ribeiro ${ }^{1}$ \\ Francisco Domiro Ribeiro Filho ${ }^{2}$
}

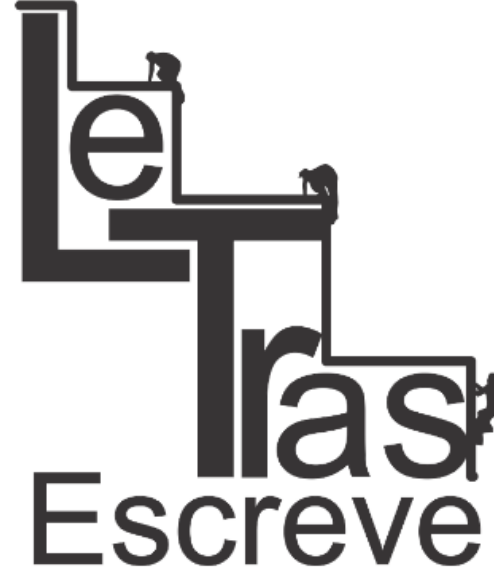

(ISSN 2238-8060)

Resumo: As mídias de informação e comunicação têm inúmeras finalidades, dentre elas a informática aplicada à educação, onde o computador é uma ferramenta pedagógica que proporciona vários recursos interativos. Nesse cenário instigante, optou-se por analisar essa metodologia no contexto da educação de jovens e adultos, mais precisamente com os educandos da terceira idade. A inserção do idoso no âmbito escolar está respaldada através da equidade, um direito assegurado pela Carta Magna e fortalecido pelo Estatuto do Idoso (Lei n. 10.741/2003). Nesse contexto, busca-se fazer um recorte investigativo acerca do processo de ensino e aprendizagem envolvendo o aludido público, no CEJA Donaninha Arruda, em Baturité - Ceará, bem como compreender o papel da informática educativa nessa relação. $O$ estudo contempla os critérios teórico-metodológicos da pesquisa bibliográfica exploratória, com constatações in situ através de observações participativas. O recorte temporal abrange os meses de janeiro a março de 2016. Para a tessitura desse trabalho, utiliza-se como aporte teórico: Freire, Gil, Mora, Valente, dentre outros. Ressalta-se que a educação gerontológica, educação direcionada ao envelhecimento, deve levar em consideração as características psicológicas, físicas e sociais inerentes a essa faixa etária. Dentre as metodologias utilizadas, a informática educativa destaca-se por favorecer aulas interativas de caráter multidisciplinar, proporcionar a inclusão digital, estimular à atividade mental e intelectual e desenvolver a relação do idoso com o seu meio social. Todavia, percebe-se que o público da terceira idade ainda é pequeno e restrito às adjacências da escola. Dentre os fatores de limitação, cumpre destacar a falta de transporte escolar direcionado a essa parcela importante da sociedade.

Palavras-chave: Educação de jovens e adultos. Interação. Idoso.

Abstract: Information and communication media have countless purposes, among them computer science applied to education, where the computer is a pedagogical tool that provides several interactive resources. In this instigating scenario, it was decided to analyze this methodology in the con-

\footnotetext{
${ }^{1}$ Mestranda em Sociobiodiversidade e Tecnologias Sustentáveis (UNILAB), Especialista em Gestão da Educação Pública (UFMG), Informática Educativa (UECE), Mídias na Educação (UFC), Licenciada em Letras (UECE), e-mail: sofiarpr@gmail.com. Pesquisa realizada com o apoio da Fundação Cearense de Apoio ao Desenvolvimento Científico e Tecnológico FUNCAP.

${ }^{2}$ Especialista em Direito Processual, Civil e Penal (Faculdade Kurios), Bacharel em Direito (FCRS). E-mail: dmpr2006@ig.om.br.
}

https://periodicos.unifap.br/index.php/letras

Macapá, v. 7, n. 4, 20 semestre, 2017 


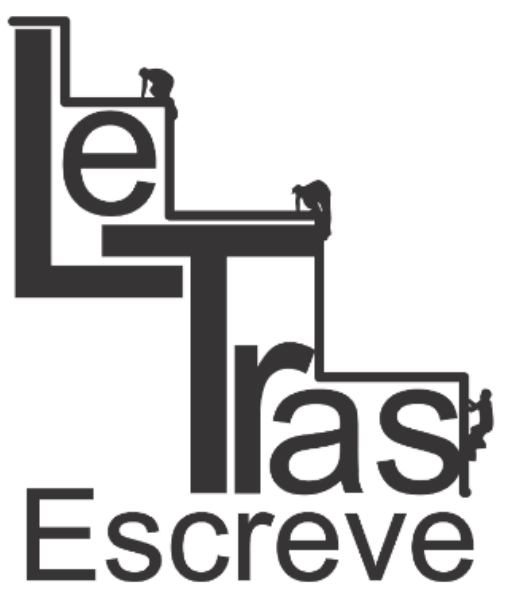

(ISSN 2238-8060)

text of the education of youths and adults, more precisely with the students of the third age. The inclusion of the elderly in school is supported by equity, a right guaranteed by the Constitution and strengthened by the Statute of the Elderly (Law No. 10.741 / 2003). In this context, it is sought to make an investigative clipping about the teaching and learning process involving the aforementioned public, in the JSB Donaninha Arruda, in Baturité - Ceará, as well as to understand the role of educational computing in this relation. The study contemplates the theoretical-methodological criteria of the exploratory bibliographic research, with in situ observations through participatory observations. The temporal cut-off covers the months from January to March 2016. For the tessitura of this work, it is used as theoretical contribution: Freire, Gil, Mora, Valente, among others. It is emphasized that gerontological education, education directed to aging, must take into account the psychological, physical and social characteristics inherent to this age group. Among the methodologies used, educational informatics is distinguished by favoring interactive classes of a multidisciplinary nature, providing digital inclusion, stimulating mental and intellectual activity and developing the relationship of the elderly with their social environment. However, it is noticed that the public of the old age is still small and restricted to the adjacencies of the school. Among the limiting factors, it is important to highlight the lack of school transportation directed to this important part of society.

Keywords: Educational computing. Interaction. Old man.

\section{Introdução}

O aumento da longevidade é fruto de uma sociedade que se preocupa com uma alimentação adequada, cuida da saúde e preza pela qualidade de vida. Deparar-se com a imagem de simpáticas vovós costurando, fazendo crochê e tricô; de vovôs jogando baralho e dominó está ficando a cada dia mais distante. Hoje, é corriqueiro encontrar idosos estudando, fazendo cursos e atuando no mercado de trabalho, ou seja, protagonistas ativos no meio em que vivem. Segundo Paulo Freire (2011, p. 18), “o alfabetizando, e não analfabeto, se insere num processo criador, de que ele é também sujeito".

De acordo com o Instituto de Geografia e Estatística - IBGE, em 2030 o Brasil será um país com população majoritariamente idosa. Nessa estatística, a população com mais de 60 anos será maior que o

https://periodicos.unifap.br/index.php/letras

Macapá, v. 7, n. 4, 2을 semestre, 2017 


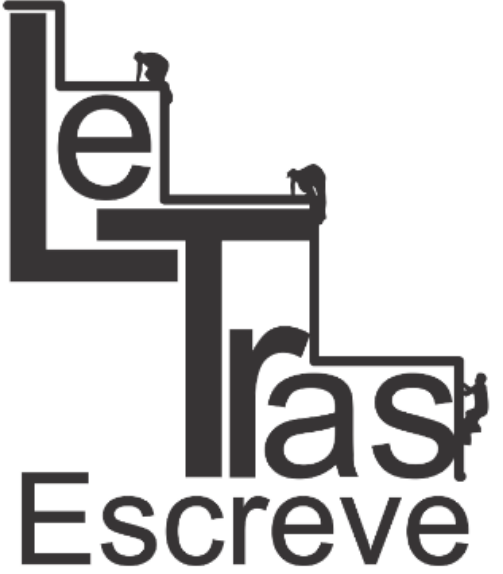

(ISSN 2238-8060)

grupo de crianças com idade inferior a14 anos. Ainda de acordo com os dados desse Instituto, em 2055 teremos mais idosos do que crianças e jovens com até 29 anos (IBGE, 2013).

Com o ritmo de vida atual e as cobranças oriundas de uma sociedade capitalista, em que a mulher deixou de dedica-se apenas aos afazeres domésticos e passou a atuar no mercado de trabalho para complementar a renda da família, e muitas vezes para suprir todas as despesas do lar, emergiu um modelo familiar que optou por ter uma quantidade menor de filhos, contribuindo para a elevação do enveIhecimento populacional.

A idade média da população em 2002 era de 29,4, passando a 33,1 anos em 2012 (IBGE, 2013). Esse quadro corrobora para que a população de idosos torne-se cada vez mais ativa e atuante. É comum encontrar alunos acima de 60 anos que decidem retornar à sala de aula para aprender e resgatar a autoestima. No CEJA Donaninha Arruda não é diferente e muitos idosos buscam essa opção. Consoante Barreto (1994, p. 3) “a informação é o instrumento modificador da consciência do homem e de seu grupo".

O CEJA Donaninha Arruda foi criado em 5 de junho de 2000 pelo Decreto no 25.904, publicado no Diário Oficial n 107 de 06 de junho de 2000, fica situado na Av. Duque de Caxias s/n, em BaturitéCE. Dista aproximadamente 98 quilômetros da capital do estado. Trata-se de uma instituição pertencente à rede oficial de ensino do estadual e é o único Centro de Educação de Jovens e Adultos (CEJA) do Maciço de Baturité, atendendo alunos oriundos dos municípios de: Baturité, Pacoti, Palmácia, Guaramiranga, Mulungu, Aratuba, Capistrano, Itapiúna, Aracoiaba, Acarape, Redenção, Barreira e Ocara.

A referida instituição tem como clientela alunos com faixa etária distintas. A matricula inicial para alunos do ensino fundamental é

https://periodicos.unifap.br/index.php/letras

Macapá, v. 7, n. 4, 20 semestre, 2017 


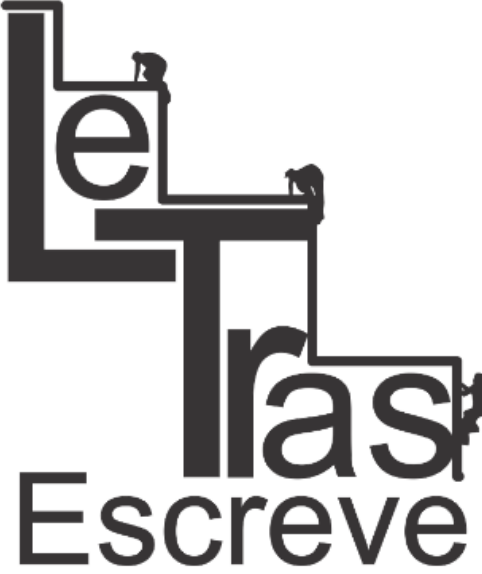

(ISSN 2238-8060)

de 15 anos; já para o ensino médio, o discente deve ter 18 anos completos. Salienta-se que o aluno mais idoso com frequência ativa tem 72 anos, segundo os dados do SIGE ${ }^{3}$ escola - 2016. Conforme relato dos educadores, é comum encontrar alunos de gerações diferentes pertencentes ao mesmo núcleo familiar. Percebe-se, num contexto geral, que a influência de familiares é um fator determinante que impulsiona os alunos da EJA ao estudo.

Segundo dados do Censo Escolar ${ }^{4}$ (2013), os idosos na Educação de Jovens e Adultos representam cerca de 3\% das matrículas do segmento no país. Convém esclarecer que a legislação específica considera idoso o indivíduo com idade igual ou superior a 60 (sessenta) anos.

No contexto atual, nota-se uma crescente dependência tecnológica da sociedade, o que favorece que o idoso busque vivenciar essa realidade, inserindo-se na era digital e usufruindo das suas benesses. Assim, a informática educativa surge como um fator motivador no processo de ensino-aprendizagem, pois junta elementos da educação formal e não formal, contribuindo para que os conhecimentos acadêmicos sejam vislumbrados através do acesso a rede mundial de computadores, a internet.

Para Soares (1997), o conjunto das redes de comunicação de massa é o maior instrumento da globalização cultural na sociedade e sua abrangência, extensão e eficácia estão na raiz das maiores transformações na virada do século. Assim sendo, a inclusão digital tornase, ao mesmo tempo, uma forma de socialização/comunicação com o mundo, facilitando as relações familiares, sociais, comerciais dentre

\footnotetext{
3 Sistema Integrado de Gestão Educacional (2016). Disponível: http://sige.seduc.ce.gov.br/saac/login.asp. Acesso: fevereiro - 2016

${ }^{4} \mathrm{O}$ censo é um relevante instrumento para a análise e levantamento de dados estatísticos educacionais, é realizado pelo Instituto Nacional de Estudos e Pesquisas Educacionais Anísio Teixeira, e vinculada ao Ministério da Educação - MEC.
}

https://periodicos.unifap.br/index.php/letras

Macapá, v. 7, n. 4, 2을 semestre, 2017 


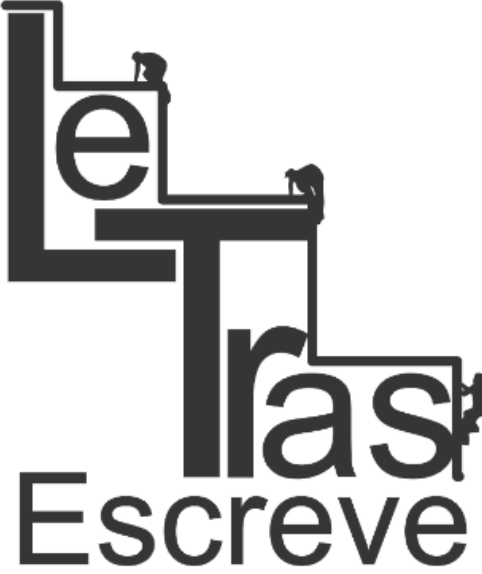

(ISSN 2238-8060) outros, ao passo que repercute também na qualidade de vida, auxiliando nos estímulos cognitivos (Bizelli et al, 2009).

O uso do laboratório de informática, no CEJA em Baturité, por alunos jovens, adultos e idosos é ao mesmo tempo um fator desafiador e motivador para todos os envolvidos. Relatam os docentes que as convivências entre um público tão heterogêneo contribuem para uma aprendizagem cooperativa, onde a troca de experiências proporciona tanto o enriquecimento dos conteúdos curriculares como o resgate da autoestima dos discentes num contexto geral.

Silveira (2010) considera que as tecnologias de informação e comunicação (TICs) contribuem na redução do isolamento, na estimulação mental e, finalmente, no bem estar da pessoa idosa. Desse modo, as aulas realizadas no LEI do CEJA são direcionadas para que o aluno, independentemente da idade, possa entrever o computador como uma ferramenta pedagógica interativa.

Depreende-se que o envelhecimento humano, por questões biológicas, traz algumas limitações, mas isso não significa incapacidade, pelo contrário, o idoso é um sujeito que tem um papel social relevante, sendo capaz de adapta-se e superar suas limitações. Dessa forma, considera-se fundamental que a educação gerontológica "seja desenvolvida de forma que o idoso evite o isolamento e tenha um envelhecimento ativo em sociedade" (SILVEIRA, PASQUALOTTI, COLUSSI, 2012).

É neste prisma que se objetiva fazer uma análise sobre o idoso na EJA, no CEJA de Baturité, e o papel da informática educativa no processo de ensino aprendizagem de alunos com idade igual ou superior a 60 anos. $O$ estudo contempla os critérios teórico-metodológicos da pesquisa bibliográfica exploratória, com constatações in loco através de observações participativas. O recorte temporal abrange os

https://periodicos.unifap.br/index.php/letras

Macapá, v. 7, n. 4, 2o semestre, 2017 
meses de janeiro a março de 2016, período onde foram acompanhadas/registradas as ações/atividades desenvolvidas no âmbito das praxes pedagógicas na referida instituição. Para Lakatos e Marconi (2003), a pesquisa quantitativa e descritiva consiste em investigações empíricas que objetivam o delineamento das características principais de um fenômeno.

Para a tessitura deste artigo, optou-se por uma pesquisa bibliográfica, exploratória e descritiva, com abordagem qualitativa, tendo como aporte teórico as contribuições acadêmicas que contemplem as temáticas: a educação de jovens, adultos e idosos; a função social da EJA; a base legal que envolve o idoso e o papel da informática educativa como ferramenta pedagógica. Dentre os autores alocados podese citar Valente (1993), Mora (2004), Freire (2011) e Gil (2011), entre outros.

Como acervos documentais foram escolhidos a Lei de Diretrizes e Bases da Educação - LDB 9.394/96; o Plano Nacional de Educação (PNE) - Lei 10.172; as Diretrizes Curriculares Nacionais para a EJA (Parecer CEB 11/2000) e o Estatuto do Idoso.

Parte-se do princípio que o idoso traz para o ambiente escolar (ISSN 2238-8060) uma vivência que pode/deve ser respeitada e contextualizada como produto cultural e que, dessa forma, conhecimento empírico e curricular devem se entrelaçar no contexto histórico, social e cultural. Para tanto, faz-se uso da andragogia (em contraposição à pedagogia, que está voltada para a educação de crianças), que é uma metodologia voltada para as práticas educacionais destinada a educação de jovens, adultos e idosos (GIL, 2011).

\section{A educação de jovens, adultos e idosos}


A escola é uma instituição de grande relevância sociocultural, porquanto é através dela que a maioria das pessoas têm acesso ao conhecimento, mudam comportamentos e, por conseguinte, constroem novos cenários onde o eterno aprendiz se torna sujeito ativo do meio em que vive. Para Gadotti $(1997$, p.5)

A escola não distribui poder, mas constrói saber que é poder. Não mudamos a história sem conhecimentos, mas temos que educar o conhecimento para que possamos interferir no mercado como sujeitos, não como objeto. $O$ papel da escola consiste em colocar o conhecimento nas mãos dos excluídos de forma crítica, porque, a pobreza política produz pobreza econômica.

Nessa perspectiva, os CEJAs oferecem um ambiente educacio-

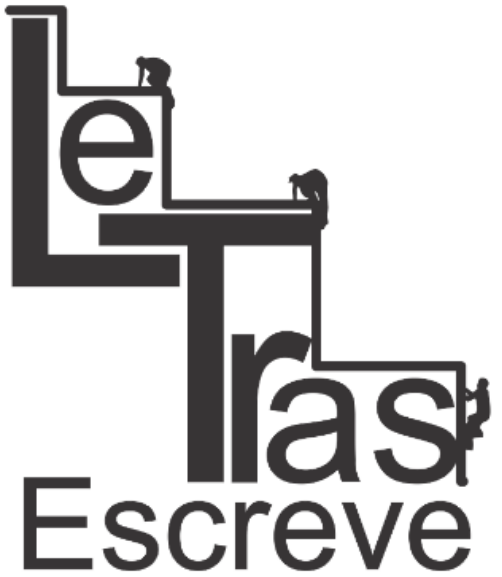

(ISSN 2238-8060) nal diferenciado, respeitando o ritmo, o tempo e o espaço de aprendizagem do educando, ao contrário da escola regular, onde esses elementos são rigidamente controlados. A base legal da EJA é a Lei 9394/96, Lei de Diretrizes e Bases da Educação Nacional, especificamente na literalidade do seu artigo 37 :

como destinada àqueles que não tiveram acesso ou à continuidade de estudos no ensino fundamental e médio na idade própria. A Constituição Federal de 1988, no artigo 208, inciso I, garante o acesso e a permanência ao ensino fundamental a todos.

Em alusão à sua estrutura funcional, o CEJA Donaninha Arruda atende a modalidade de ensino semi-presencial, onde o aluno dispõe de três turnos de atendimento individual e personalizado. Consoante a LDB (1996), a escola deve oferecer oportunidades educacionais apropriadas, consideradas as características do alunado, seus interesses, condições de vida e de trabalho. Para Marques (1992, p.195) "a escola é um espaço de vivências democráticas, orgânico e ao mesmo 
tempo e criativo".

A instituição conta com uma média de 1.000 atendimentos mensais (SIGE, 2016), sendo que a grande maioria dos alunos são oriundos de municípios vizinhos. A clientela proveniente de Baturité representa cerca de $20 \%$ do público e, destes, em média $10 \%$ têm idade acima de 60 anos. Enfatiza-se que a matrícula ocorre constantemente e fica ativa por dois meses. Caso o aluno se ausente por um período maior, será necessário reativá-la.

Ao contrário das escolas tradicionais, no CEJA não há aulas regulares, mas, sim, atendimentos. O material didático é gratuitamente disponibilizado em sistema de empréstimo para o aluno, tornando-se protagonista do seu ritmo de estudo. Como preconiza Paulo Freire (2000), figura emblemática no contexto educacional da EJA, o ato educativo é inerente ao ser humano.

O discente estuda a seu tempo e, ao sentir-se preparado, comparece à escola, procede a uma revisão do conteúdo com o professor da área e este, por sua vez, autoriza (ou não) o aluno a submeter-se às provas.

Dessa forma, a EJA desempenha um papel social relevante ao (ISSN 2238-8060) viabilizar a educação básica para pessoas que, por algum motivo, foram impossibilitadas de frequentar uma instituição de ensino regular. Segundo dados da Pesquisa Nacional por Amostra de Domicílios (Pnad)/IBGE (2012), a EJA atende cerca de 100 mil idosos (com 60 anos ou mais), mas a faixa etária que predomina configura-se entre 15 a 44 anos, o que corresponde a $86,1 \%$ de suas matrículas.

É comum ouvir entre os professores do CEJA Baturité, principalmente dos docentes da área de linguagens e códigos, relatos que os alunos da terceira idade querem estudar (ou dar continuidade aos estudos outrora interrompidos) com o intuito de lerem a bíblia, do- 


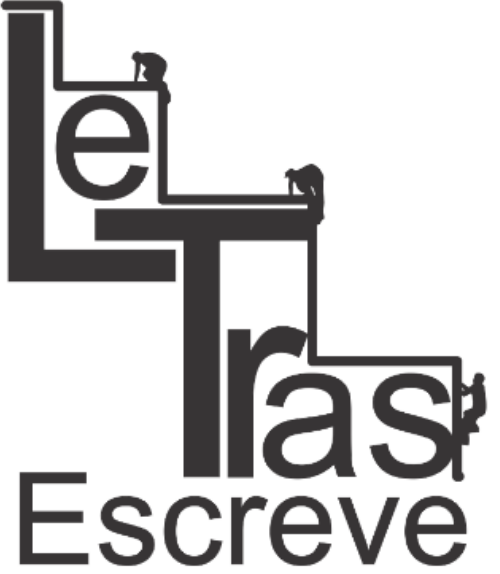

(ISSN 2238-8060) cumentos, bulas de remédios e rótulos de produtos, sem precisarem do auxílio dos familiares ou amigos, ou seja, procuram ser mais independentes e, consequentemente, viverem melhor. Para Duarte (1999), a ideia central sobre o envelhecimento na atualidade não é a apenas a longevidade, mas sim a qualidade de vida.

A educação de jovens, adultos e idosos é uma realidade que traz para o contexto educacional um novo paradigma, uma forma de rever a aprendizagem, que transcende a idade cronológica, onde os alunos da terceira idade mostram-se atuantes, engajados, ativos e produtivos. Como exemplo, pode-se citar um casal com mais de sessenta anos que frequenta o CEJA Baturité. A princípio, tinham sérias limitações cognitivas, mas hoje conseguem "assinar o nome", produzir textos e costumam utilizar o laboratório de informática da instituição como ambiente virtual de aprendizagem.

\section{Idade cronológica, maturidade e o desenvolvimento psicossocial}

A idade de um ser, por si só, não fornece elementos para compreender os processos psicológicos, posto que cada pessoa tem um ritmo de desenvolvimento psicossocial diferente. Geralmente, de forma simplória, a idade é vista apenas pelo tempo cronológico que faz referência ao número de anos decorridos do nascimento até uma data específica. Entretanto, é preciso considerar que há diferentes formas de entender e conceituar idade. Para Irigaray e Schneider (2008, p. 585).

A etapa da vida caracterizada como velhice, com suas peculiaridades, só pode ser compreendida a partir da relação que se estabelece entre os diferentes aspectos cronológicos, biológicos, psicológicos e sociais. Essa interação institui-se de acordo com as 
condições da cultura na qual o indivíduo está inserido. Condições históricas, políticas, econômicas, geográficas e culturais produzem diferentes representações sociais da velhice e também do idoso. Há uma correspondência entre a concepção de velhice presente em uma sociedade e as atitudes frente às pessoas que estão envelhecendo.

Dados os múltiplos elementos caracterizadores desse período da vida humana, necessário se faz descrever as principais ocorrências. A primeira e mais conhecida é a biológica, que está relacionada ao tempo de vida, e normalmente é expressa em anos; a idade psicológica, que tem relação com o senso subjetivo de idade, ou seja, a forma de encarar os desafios. Enquanto a terceira surge do equilíbrio entre

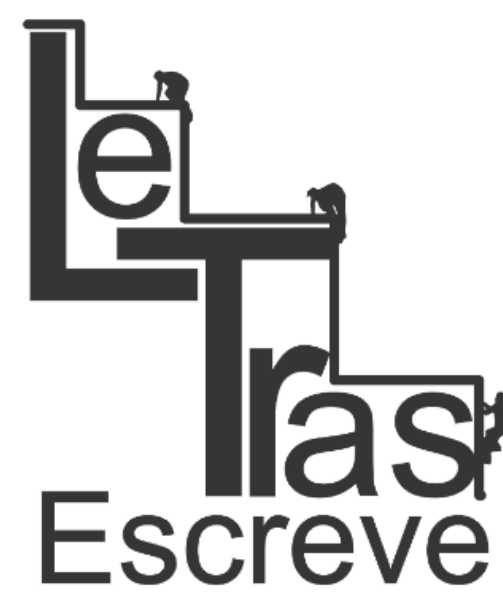

(ISSN 2238-8060) a idade biológica e psicológica, resultando na idade funcional, que está diretamente relacionada a capacidade de autonomia/independência do indivíduo (Duarte, 1999).

Reforça San Martín e Pastor (1996) que a velhice não é definida por simples cronologia, mas pelas condições físicas, funcionais, mentais e salutares das pessoas, ou seja, pode-se observar diferentes idades biológicas e psicológicas em indivíduos com a mesma idade.

Nesse contexto urge evidenciar ainda que a idade pode ser definida em períodos, sendo: a infância, que vai do nascimento até os onze anos de idade; a adolescência, dos doze aos vinte e, a fase adulta, cujo início é aos vinte e um anos. Já a velhice, conforme o Estatuto do Idoso (2003), começa a partir dos 60 anos. Diga-se de passagem, estes últimos ocupam cada vez mais espaço no nosso meio e, diga-se de passagem, de forma participativa. Cabe esclarecer que o Brasil, até 2025, será o sexto país em número de idosos (World Health Organization - WHO, 2005).

Ante o exposto, ressalta-se que a inserção do idoso no contexto educacional, associado ao uso das tecnologias de informação e 


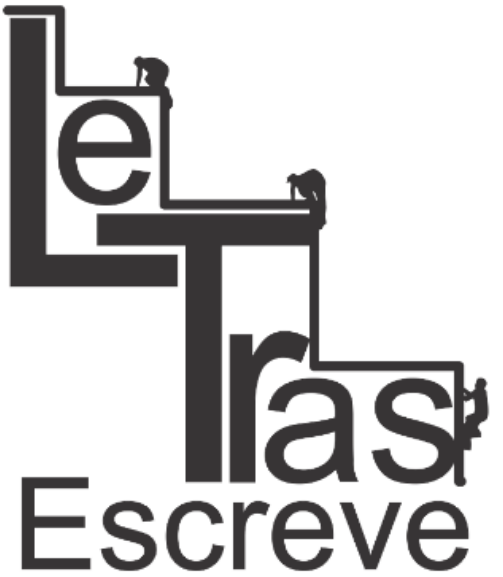

(ISSN 2238-8060)

comunicação, contribui para o desenvolvimento social e cognitivo do indivíduo. Assim, "Homens e mulheres que se preparam para a velhice e se adaptam a mudanças fazem um melhor ajuste em sua vida depois dos 60 anos" (WHO, 2005, p.27).

Depreende-se que a busca por conhecimento faz do idoso um ser psicologicamente "novo", ativo e atuante. Entretanto, convém salientar que, com o passar dos anos, é indiscutível que há mudanças e declínios na estrutura biológica. O cérebro da pessoa idosa apresenta diferenças morfológicas em relação ao do indivíduo jovem, o seu tamanho é menor, em média, e consequentemente possui menor peso, mas as experiências conquistadas com a maturidade são fatores que compensam essa realidade, Lent (2001).

Para Mora (2004) o envelhecimento é um processo único e individual, não é regido somente por fatores genéticos, sofre uma forte influência dos fatores ambientais e do próprio desenvolvimento do indivíduo. Nesse contexto, Paulo Freire $(2003$, p.73) ressalta que a educação deve ser permanente:

\begin{abstract}
Diferentemente dos outros animais, que são apenas inacabados, mas não são históricos, os homens se sabem inacabados. Têm a consciência de sua inconclusão. Aí se encontram as raízes da educação mesma, como manifestação exclusivamente humana. Isto é, na inconclusão dos homens e na consciência que dela tem. Daí que seja a educação um quefazer permanente. Permanente, na razão da inconclusão dos homens e do devenir da realidade.
\end{abstract}

Percebe-se que o ser humano está em constante evolução e cada etapa da existência traz suas peculiaridades inerentes ao contexto sociocultural em que o indivíduo está inserido. É esse conhecimento que deve ser respeitado e associado ao contexto escolar. Para Paiva (1999. p. 522) é imprescindível que o educando tenha "condi- 


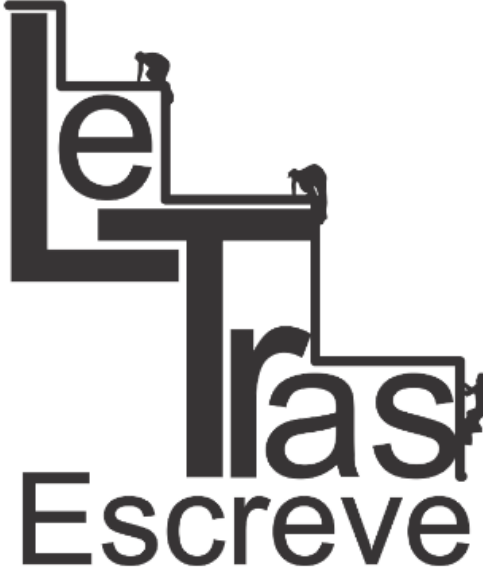

(ISSN 2238-8060)

ções de acompanhar a velocidade e complexidade do mundo contemporâneo, que exige aprender continuadamente, por toda a vida, ante o avanço do conhecimento e a permanente criação de códigos, linguagem e símbolos e de sua recriação diária".

Aqui a importância da informática aplicada à educação, ao surgir como ferramenta pedagógica que possibilita "testar ideias ou hipóteses, que levam à criação de um mundo abstrato e simbólico, ao mesmo tempo em que permite introduzir diferentes formas de atuação e interação entre as pessoas" (ALMEIDA, 2000, p.79).

Como o público frequentador do CEJA Baturité é heterogêneo, formado por educandos de localidades distintas, oriundos da zona urbana e rural, e com faixa etária diversificada, o ambiente se torna propício para a troca de saberes, peculiaridade esta riquíssima para o processo de ensino e aprendizagem. De acordo com os dados do SIGE/2016, o aluno mais novo tem 15 e o mais idoso tem 72 anos de idade.

Essa realidade é ao mesmo tempo um desafio e um fator motivador para os docentes que buscam trabalhar os conteúdos curriculares de uma forma dinâmica e contextualizada, respeitando o ritmo de cada aluno, prezando por uma metodologia pautada nas necessidades e interesses do educando. Para Gadotti (2007, p. 13), “o professor se tornou um aprendiz permanente, um construtor de sentidos, um cooperador, e, sobretudo, um organizador da aprendizagem".

De acordo com Brandão (2002, p.187), "a educação é essencial e é insubstituível". Dentre todas as práticas culturais da vida humana e da experiência de sociedades como a nossa, dificilmente alguma outra será tão insubstituível quanto a educação". Nesta perspectiva, Gadotti (1997) descreve que os jovens e adultos trabalhadores lutam para superar condições precárias de vida, que estão na raiz do pro-

https://periodicos.unifap.br/index.php/letras

Macapá, v. 7, n. 4, 20 semestre, 2017 
blema do analfabetismo.

\section{O direito dos idosos e a legislação}

A garantia de acesso e permanência no ensino fundamental a todos os indivíduos está resguardada pela Constituição Federal de 1988, em seu artigo 208, “O dever do Estado com a educação será efetivado mediante a garantia de: I - ensino fundamental obrigatório e gratuito, assegurada, inclusive, sua oferta gratuita para todos os que a ele não tiveram acesso na idade própria; II - progressiva universalização do ensino médio gratuito[...]".

A Carta Magna traz vários artigos que fazem referência ao ido-

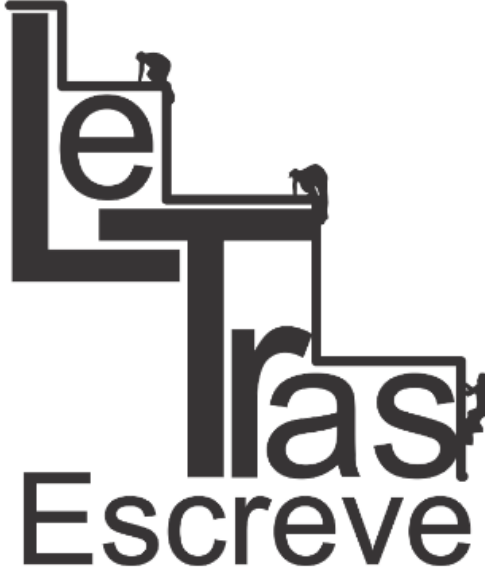

(ISSN 2238-8060) so e seus direitos, entre eles, pode-se citar: o artigo 1으, inciso III, retrata o princípio da "dignidade da pessoa humana", assegurando os direitos fundamentais de todos. A dignidade é o "núcleo axiológico do constitucionalismo contemporâneo, constitui o valor constitucional supremo que irá informar a criação, a interpretação e a aplicação de toda a ordem normativa constitucional" (CUNHA JÚNIOR; NOVELINO, 2012, p. 12).

No artigo 3으, inciso IV, a Lei Maior ressalta um dos objetivos fundamentais da República Federativa do Brasil que é: promover o bem estar de todos, sem preconceitos de origem, raça, sexo, cor, idade e quaisquer outras formas de discriminação". Nessa perspectiva, o idoso tem seus direitos resguardados e, dessa forma, devem ser respeitados e vivenciados, mormente no ambiente da escola.

Já no artigo 203, inciso I, que trata da assistência social a qual será prestada a quem dela necessitar, independente de contribuição à seguridade social, e tem por objetivos: I- a proteção à família, à maternidade, à infância, à adolescência e à velhice [...]. Em seguida, o artigo 205 descreve que: 


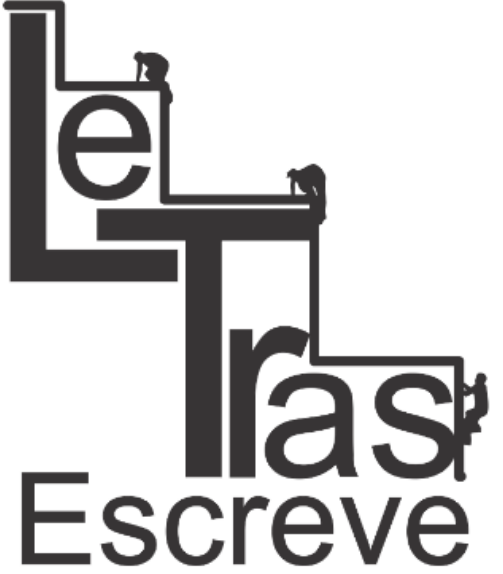

(ISSN 2238-8060) a educação é citada como direito de todos e dever do Estado e da família, e que a mesma será promovida e incentivada com colaboração da sociedade, visando ao pleno desenvolvimento da pessoa, seu preparo para o exercício da cidadania e sua qualificação para o trabalho.

O artigo 230 deixa explícito que a família, a sociedade e o Estado têm o dever de amparar as pessoas idosas, assegurando a sua participação na comunidade defendendo sua dignidade e bem-estar e garantindo-lhes o direito à vida.

No contexto educacional, o idoso tem seu direito à educação garantido pela Lei 9394/96, Lei de Diretrizes e Bases da Educação Nacional (LDB). A referida norma tem um potencial inclusivo bem amplo, abrangendo jovens, adultos e idosos. A título de esclarecimento, o idoso, no contexto da EJA, é compreendido como adulto, como pode ser observado nas Diretrizes Curriculares Nacionais para a Educação de Jovens e Adultos, no Parecer da Câmara de Educação Básica (CEB 11/2000),

\begin{abstract}
A barreira posta pela falta de alcance à leitura e à escrita prejudica sobremaneira a qualidade de vida de jovens e de adultos, estes últimos incluindo também os idosos, exatamente no momento em que o acesso ou não ao saber e aos meios de obtê-lo representam uma divisão cada vez mais significativa entre as pessoas. [...] O estado de adulto (adultícia) inclui o idoso.
\end{abstract}

Como se infere, o parecer enquadra o idoso como uma faixa etária extensiva à noção de adulto, não levando em consideração suas especificidades, ritmo de aprendizagem, cabendo ao educador trabalhar de forma dinâmica e contextualizadas as diferenças etárias inseridas/vivenciadas nas turmas de EJA, no CEJA de Baturité.

Na organização curricular da EJA em estudo, percebe-se que o 
currículo educacional contempla a Lei $10.741 / 2003$, precisamente no seu art. 22, que traz o seguinte texto: “Nos currículos mínimos dos diversos níveis de ensino formal serão inseridos conteúdos voltados ao processo de envelhecimento, ao respeito e à valorização do idoso, de forma a eliminar o preconceito e a produzir conhecimentos sobre a matéria".

Nessa perspectiva, surge o webcurriculo, uma ferramenta pedagógica que une currículo formal às tecnologias de informação e comunicação (TIC's), onde a comunicação interativa, através da internet, favorece tanto a aprendizagem curricular como a inclusão digital do alunato.

\section{A informática Educativa no CEJA Donaninha Arruda}

A informática está inserida no dia a dia, de uma forma direta ou indireta. A presença de computadores é algo comum no contexto sociocultural contemporâneo. Essa tendência atingiu também a escola e, hodiernamente, o uso das tecnologias de informação e comunicação é ferramenta importante de múltiplo uso a propiciar que docentes e discentes se tornem sujeitos ativos no processo ensino/aprendizagem. De acordo com Borges (1999, p. 136):

A Informática Educativa se caracteriza pelo uso da informática como suporte ao professor, como um instrumento a mais em sua sala de aula, no qual o professor possa utilizar esses recursos colocados a sua disposição. Nesse nível, o computador é explorado pelo professor especialista em sua potencialidade e capacidade, tornando possível simular, praticar ou vivenciar situações, podendo até sugerir conjecturas abstratas, fundamentais a compreensão de um conhecimento ou modelo de conhecimento que se está construindo. 
Desta feita, percebe-se o aluno vivencia o aprendizado de uma forma mais ampla e interativa. Freire $(2002$, p. 14) ressalta que "nas condições de verdadeira aprendizagem os educandos vão se transformando em reais sujeitos da construção e da reconstrução do saber ensinado ao lado do educador, igualmente sujeito do processo".

Visando maior eficiência, as aulas no LEI são agendadas previamente entre os professores da disciplina e o regente do laboratório. Assim, é possível conciliar diferentes realidades num mesmo ambiente, direcionando atividades de acordo com o perfil do educando. Todavia, no final da aula, as atividades são compartilhadas através de debate, como forma de socializar/acrescentar experiências.

Ainda Segundo Novaes (1997, p. 144), “hoje não basta o co-

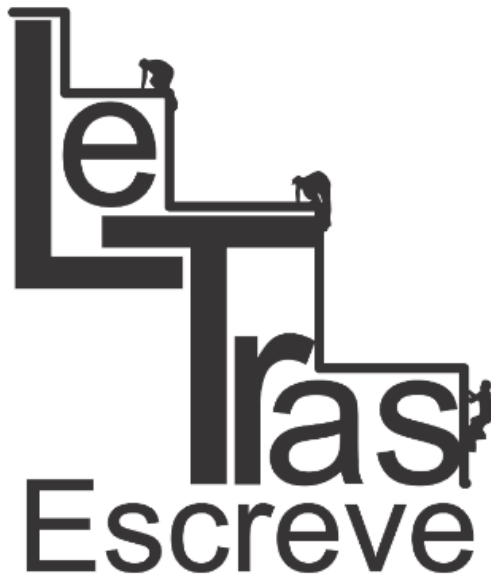

(ISSN 2238-8060) nhecimento: de fundamental importância é o exercício da capacidade de pensar, imaginar e criar. É preciso ampliar o leque das habilidades a serem estimuladas e acentuar a satisfação e o prazer de aprender e criar". Nessa perspectiva, os alunos são incentivados a desenvolver a habilidade da leitura crítica, para em seguida fazer a produção textual de uma forma interativa e contextualizada. Para Valente (1993, p. 26):

[...] A informática educacional é o processo que coloca o computador e sua tecnologia a serviço da educação. Portanto, todos os aspectos e as variáveis neste processo deverão estar subordinados à consideração de que a essência da informática educacional é de natureza pedagógica, buscando melhorias dos processos de ensino aprendizagem de forma a levar o aluno a aprender, o professor a orientar e auxiliar esta aprendizagem, tornando-o apto a discernir sobre a realidade e nela atuar.

Nesse sentido, o webcurrículo apresenta-se como um currículo que se desenvolve por meio das tecnologias digitais de informa- 
ção e comunicação, especialmente mediado pela internet (ALMEIDA, 2000). Para tanto, salienta-se que a interdisciplinaridade é outro fator importante para as aulas no LEI, pois além de propiciar o diálogo entre os saberes, possibilita que cada pesquisador possa revelar a sua própria potencialidade, a sua própria competência (FAZENDA, 2008).

Para Freire (2002, p. 15) "formar é muito mais do que puramente treinar o educando no desempenho de destrezas". Para exemplificar algumas ações realizadas no LEI, optou-se por descrevê-las em forma de tabela.

Tabela 1 - O uso do computador como ferramenta pedagógica no processo de ensino e aprendizagem.

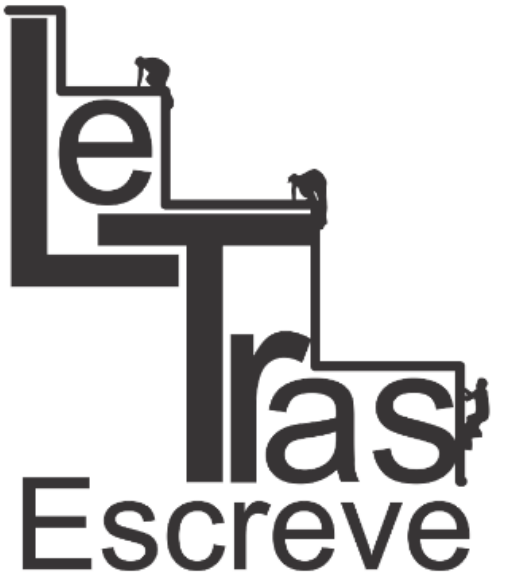

(ISSN 2238-8060)

\begin{tabular}{|l|l|}
\hline Área do conhecimento & Iteratividade no Laboratório \\
\hline Linguagens e Códigos & Pesquisa temáticas, \\
& $\begin{array}{l}\text { Produção textual: "Projeto LeiturAção"; } \\
\text { Confecção de slides, } \\
\text { Simulados e aulas on-line de redação. }\end{array}$ \\
\hline Ciências Humanas & Visita a museus virtuais, \\
& Leitura dinâmicas: acesso a bibliotecas virtuais, \\
& Aulas de cartografia: mapas, \\
& A Lei 10.639: "Projeto Nossa Cultura", \\
& Participar de Vídeos conferências. \\
\hline Ciências da Natureza & Construção de tabelas e gráficos, \\
& A tabela periódica interativa, \\
& O corpo humano e o papel da alimentação, \\
& Acesso a laboratórios virtuais de química. \\
\hline
\end{tabular}

Fonte: autora.

Além das ações supracitadas, registra-se que os jogos educativos, que abrangem questões de português e matemática, são atividades que os idosos costumam acessar no laborratório. Para Bizelli e colaboradores (2009), a informática ajuda a conservar a memória, estimula a socialização e põe o idoso em contato com o mundo moderno. Esses procedimentos educativos têm despertado o interesse e elevado a autoestima dos usuários. De acordo com o relato do professor responsável pelo LEI, uma das alunas (com mais de 60 anos) passou a frequentar o CEJA para realizar o sonho de voltar a estudar. 
Saraiva $(2004$, p. 31) preleciona que a contínua atualização do conhecimento é necessária frente ao ritmo acelerado da mudança social e tecnológica, além de diminuir o fosso cultural da terceira idade, já que, devido à redução dos índices de natalidade e elevação da expectativa de vida, a população tende ao envelhecimento.

Visando atender ao público heterogêneo que frequenta o LEI, as atividades são planejadas em encontros mensais e semanais, com o escopo de fortalecer as aulas expositivas realizadas em sala de aula. Vale esclarecer que o uso da informática educativa está contemplada no Projeto Político Pedagógico (PPP) e no plano anual de atividades da referida instituição.

Salienta-se que a área de linguagens e códigos, nos meses em

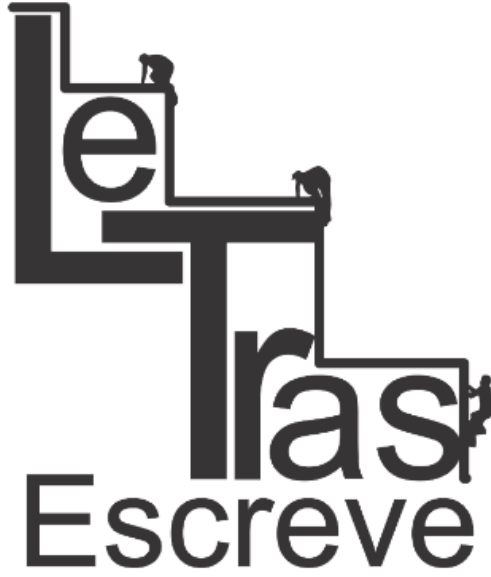

(ISSN 2238-8060) estudo, trabalhou o "Projeto LeiturAção", estimulando a leitura crítica de texto on-line e a produção textual. Considera-se que "a leitura é um processo no qual o leitor realiza um trabalho ativo de construção do significado do texto, a partir de seus objetivos, do seu conhecimento sobre o assunto, sobre o autor, de tudo o que sabe sobre a língua [...]" (PCN 1997, p. 53).

Schneuwly (2004) considera que o ensino-aprendizagem de gêneros textuais na escola favorece o desenvolvimento de capacidades individuais, permitindo a comunicação em diferentes situações, através da autoformação. Convém salientar que os alunos da terceira idade costumam acessar, no ambiente digital, sites que abordam temáticas relacionadas a atualidades, religião, saúde e bem estar.

A infraestrutura do LEl é composta por dezessete computadores, acesso à internet, ambiente climatizado, boa iluminação e uma impressora conectada à rede. Ressalte-se, ainda, que o sistema operacional utilizado nos laboratórios é o "Linux Educativo", fato este que, a princípio, causa estranheza, pois a grande maioria dos fre- 


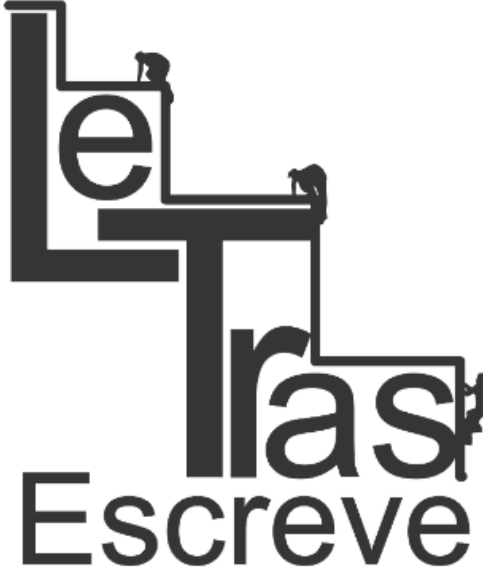

(ISSN 2238-8060) quentadores costumam utilizar, de forma direta ou indireta, o sistema operacional Windows da Microsoft.

No entanto, sabe-se que se faz necessário para o bom desempenho do processo de aprendizagem algo mais que um ambiente estruturado. Para Flores (1996, p. 86-89) “Nenhum equipamento ou programa substitui um bom projeto educacional". Nesse sentido, a eficácia do processo de ensino e aprendizagem vivenciado no LEI está pautado na didática que contempla o tripé: docente de sala de aula, regente do laboratório e uma didática direcionada. Além dos elementos elencados, o uso das TICs é um fator que impulsiona o docente a torna-se um professor-pesquisador.

Como metodologia os docentes utilizam a andragogia, que é "um conjunto de princípios de aprendizagem de adultos que se aplicam a todas as situações que envolvem este discente" (GIL, 2011, p.12), pois entende-se que o adulto, principalmente o idoso, deve ser tratado como adulto, evitando uma metodologia que o "infantilize".

Respeitando os pilares da educação que são: "aprender a conhecer, aprender a fazer, aprender a viver juntos e aprender a ser" (DELLORS, 1998, p. 90).

Para Oliveira (2009) muitas vezes o idoso é colocado numa situação típica de marginalização social. Nesse sentido, a inclusão do aluno idoso no contexto educacional favorece qualidade de vida, eleva a autoestima e proporciona o contato entre gerações.

\section{Considerações finais}

Ao revisar as contribuições acadêmicas em torno da temática e os dados catalogados in situ, percebe-se que, inobstante a quantidade de alunos com idade acima de sessenta anos não ser tão expressi-

https://periodicos.unifap.br/index.php/letras

Macapá, v. 7, n. 4, 2을 semestre, 2017 


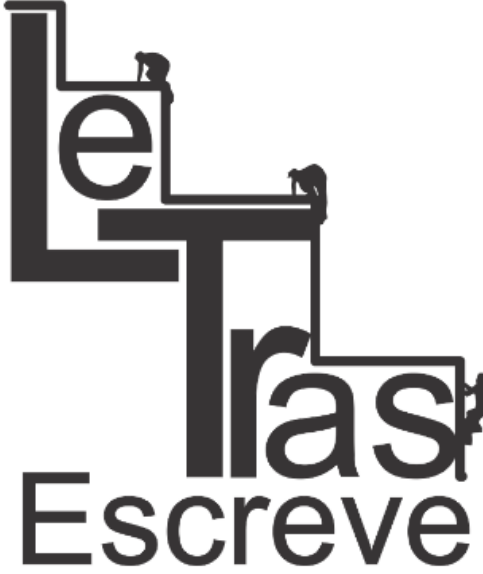

(ISSN 2238-8060) va como as outras faixas etárias, é comum encontrá-los envolvidos nas atividades pedagógicas do CEJA. A força de vontade e entusiasmo desses idosos os tornam exemplo de superação e estímulo para seus pares e demais educandos. Segundo Kachar (2001), o idoso do século XXI mudou, deixou de viver de lembranças e tornou-se uma pessoa ativa que intervém nas mudanças socioculturais e políticas.

Um exemplo a ser relatado é o do aluno mais idoso da instituição, com 72 anos, o qual participa das aulas ministradas no LEI, das oficinas de teatro e, ainda, compõem o grupo de dança regional da escola. Não bastasse, o referido aluno passou a frequentar a escola para incentivar o sobrinho a realizar o sonho de concluir a educação básica. É notável que no campo das práticas e interações o processo de ensino e aprendizagem toma forma, indo além dos limites físicos da sala de aula (FREIRE, 2000),

Outro dado merecedor de reflexão é o objetivo buscado pelos alunos da EJA, que normalmente visam recuperar um "tempo perdido". Nessa perspectiva, pressupõe-se que a maturidade desses estudantes proporciona uma relação de engajamento com as temáticas que envolvem o indivíduo e a coletividade. Assim, as diferenças de saberes, culturas e a heterogeneidade das turmas da EJA são, concomitantemente, um desafio e um fator motivador, tanto para os educandos como para os educadores.

Como na EJA o corpo discente apresenta características variadas, haja vista a margem das idades, o histórico de repetência, a evasão escolar e as reprovações, as práticas pedagógicas adotadas seguem o modelo da andragogia, a qual busca orientar/ensinar o adulto através da autogestão, prezando pelo respeito à idade e à maturidade intelectual de cada indivíduo.

Nesse diapasão, uma prática que se destaca no processo de

https://periodicos.unifap.br/index.php/letras

Macapá, v. 7, n. 4, 20 semestre, 2017 


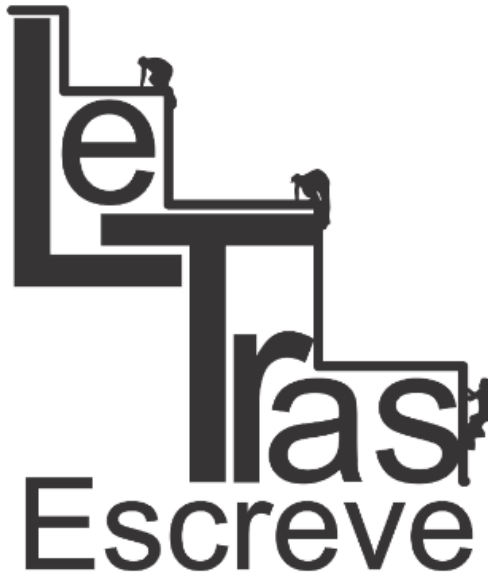

(ISSN 2238-8060)

ensino e aprendizagem da instituição em estudo são os projetos pedagógicos, onde se trabalha por área do conhecimento ou de forma interdisciplinar, sendo que muitas ações estão registradas no plano anual de atividades. No recorte temporal em que a pesquisa foi realizada estavam em andamento os projetos "LeiturAção", que tem como foco a leitura, interpretação e produção textual, e "Nossa Cultura", voltada para a Lei $10.639 / 2003$, que trabalha a cultura afrobrasileira através de ações afirmativas, com pesquisas interativas, confecção de slides e apresentação de seminários. Segundo Freire, os alunos devem compreendem-se como seres culturais, originários e produtores de cultura (FREIRE, 1978, 1992, 2002).

Para a realização dos projetos supracitados, infere-se que a informática educativa tem um papel relevante como ferramenta pedagógica dinamizadora do processo de ensino-aprendizagem, pois propicia a pesquisa interativa, promove a comunicação entre os pares (on line) e permite a troca de experiência através da aprendizagem cooperativa (interação aluno-aluno). Dentre os alunos envolvidos nas atividades, o idoso destaca-se pelo seu interesse, motivação e as contribuições empíricas. Dessa forma, os conteúdos curriculares tornamse mais ricos e as aulas mais atrativas.

Frente a esta realidade educacional, convém evidenciar que há uma constante oscilação nos índices de alunos na instituição, fato também corrente entre os idosos. Outro fator que deve ser considerado é que, apesar da abrangência da instituição, os alunos da terceira idade estão restritos, na grande maioria, à zona urbana de Baturité, mais precisamente aos bairros próximos ao colégio. Percebe-que os limites impostos naturalmente pela idade e a falta de transporte especifico também contribuem para este cenário.

https://periodicos.unifap.br/index.php/letras

Macapá, v. 7, n. 4, 20 semestre, 2017 


\section{Referências}

ALMEIDA, M. E. de. Informática e formação de professores. Brasília: Ministério da Educação, 2000.

BIZELLI, M.H.S.S.; BARROZO, S.; TANAKA, J.S.; SANDRON, D.C. Informática para a terceira idade - características de um curso bem sucedido. Revista Ciência em Extensão, São Paulo, v. 5, n. 2, p. 4-14, 2009.

BARRETO, A. de A. A questão da informação. São Paulo em Perspectiva. São Paulo, Fundação Seade, v.8, n.4, out.-dez., 1994, p.3-8.

BORGES, N. H. Uma classificação sobre a utilização do computador pela escola. Revista Educação em Debate. Ano 21, v.1, n. 27, p. 135138, Fortaleza, 1999.

BRASIL, Lei no 10.741, Estatuto do idoso. De 1의 de outubro de 2003.Senado Federal. Disponível em: http://www.planalto.gov.br/ ccivil_03/leis/2003/L10.741.htm. Acesso em: 19 de abr 2017.

Constituição da República Federativa do Brasil de 1988. Dis-

ponível: http://www.planalto.gov.br/ccivil_03/constituicao/consti tuicao.htm. Acesso em: 15 abr 2017.

(ISSN 2238-8060) , Lei de Diretrizes e Bases da Educação Nacional (LDB), Lei no 9.394, de 20 de dezembro de 1996. Disponível: http://portal.mec.gov.br. Acesso em: 02 abr 2017.

, Parecer CNB/CEB 11/2000. De 5 de maio de 2000. Dispõe sobre as diretrizes curriculares nacionais para a educação de jovens e adultos, Brasília MEC. 2000. , Instituto Nacional de Estudos e Pesquisas Educacionais Anísio

Teixeira

Censo Escolar da Educação Básica 2013: resumo técnico / Instituto Nacional de 
39 p. : tab.

, Instituto Brasileiro de Geografia e Estatística - IBGE (2013).

, Parâmetros Curriculares Nacionais - PCN. Língua portugue-

sa. Secretaria de Educação Fundamental. Brasília, v.2, 144 p., 1997. Lei no 10.639. De 9 de janeiro de 2003. Disponível: http://www.planalto. gov.br/ccivil_03/leis/2003/L10.639.htm. Acesso em: 02 abr 2017. Instituto Brasileiro de Geografia e Estatística - IBGE. Pesquisa Nacional por Amostra de Domicílios - PNAD (2012). Disponível em: http://www.ibge.gov.br/home/estatistica/populacao/trabalho erendimento/pnad2012/. Acesso: 20 mar 2017.

CUNHA JUNIOR, Dirley da; NOVELINO, Marcelo. Constituição Federal para concursos. 3. Ed. Salvador: Juspodivm, 2012.

DELORS, J. Educação um tesouro a descobrir. UNESCO, 1998. Disponível em: <http://www.pucsp.br. Acesso: 20 abr 2017.

DUARTE, L. R. S. Idade Cronológica: mera questão referencial no processo de envelhecimento. Estud. Interdisciplinar e envelhecimento, Porto Alegre, v.2, p.35-47, 1999.

FAZENDA, I. C. A. (org.) Didática e interdisciplinaridade. 13a ed. São (ISSN 2238-8060) Paulo: Papirus, 2008.

FLORES, A. M. A informática na educação: uma proposta pedagógica. Tubarão, 1996. 86 p. Monografia (Especialização em Informática). Coordenadoria do Curso de Especialização em Informática.

FREIRE, P. Pedagogia do oprimido. 6 ed. Rio de Janeiro: Paz e Terra, 1978.

Pedagogia da esperança: um reencontro com a pedagogia do oprimido. Rio de Janeiro: Paz e Terra, 1992. 245 p. . Pedagogia da autonomia: saberes necessários à prática educativa. 25. ed. São Paulo: Paz e Terra, 2002. 165 p. 


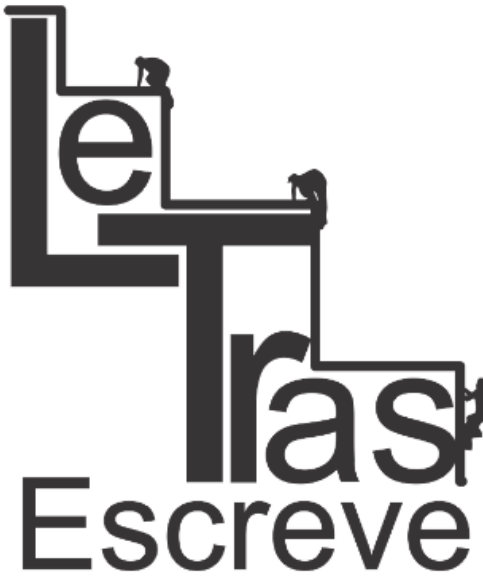

(ISSN 2238-8060)
A importância do Ato de Ler - em três artigos que se completam. Ed. Cortez, São Paulo, 51ํ Edição 2011 - Páginas 41 à 43 GADOTTI, M. Lições de Freire. Revista da Faculdade de Educação. São Paulo, vol. 23 n. 1-2 Jan./Dec. 1997.

GADOTTI, M. A escola e o professor: Paulo Freire e a paixão de ensinar. São Paulo: Publisher Brasil, 2007.

GIL, A. C. Didática do Ensino Superior. São Paulo: Atlas, 2011.

IRIGARAY, T. Q.; SCHNEIDER, R. H. Participação de idosas em uma Universidade da Terceira Idade: motivos e mudanças ocorridas. Psicologia: Teoria e Pesquisa, Brasília, v. 24, n. 2, p. 211-216, 2008.

KACHAR, V. A Terceira Idade e o Computador: Interação e Produção no Ambiente Educacional Interdisciplinar. 206f. Tese de Doutorado em Educação. Pontifícia Universidade de São Paulo, São Paulo, 2001. LAKATOS, E. M. e MARCONI, M. A. Fundamentos da Metodologia Científica. 5a. ed. São Paulo: Atlas, 2003.

LENT, R. Cem bilhões de neurônios: conceitos fundamentais de neurociência. São Paulo: Atheneu; 2001.

MARQUES, M. O. A formação do profissional da Educação. ljuí: Unijuí, 1992.

SILVEIRA, M. M. da; PASQUALOTTI, A.; COLUSSI, E. L. Educação gerontológica, envelhecimento humano e tecnologias educacionais: reflexões sobre velhice ativa.

MORA F. Quase no final: como funciona o cérebro envelhecido. In: Mora F, ed. Continuum: como funciona o cérebro? Trad. Maria Regina Borges Osório. Porto Alegre: Artmed; 2004.

NOVAES, M. H. Psicologia da terceira idade. Rio de Janeiro: Nau. 1997.

OLIVEIRA, Ramon de. Informática educativa: dos planos e discursos à sala de aula. 14. ed. Campinas: Papirus, 2009.

https://periodicos.unifap.br/index.php/letras

Macapá, v. 7, n. 4, 2을 semestre, 2017 
PAIVA, J. Tramando concepções e sentidos para redizer o direito educação de jovens e adultos. In: Revista Brasileira de Educação. v. 11, n. 33. p. 519 - 566. Set./dez. 2006

SARAIVA, I. S. (2004). Educação de jovens e adultos: dialogando sobre aprender e ensinar. Passo Fundo: UPF.

SAN MARTíN, H., \& PASTOR, V. (1996). La epidemiologia de la vejez. Rio de Janeiro: Atheneu. São Paulo: Autores Associados: Cortez, 1989. SCHNEUWLY, B.; DOLZ, J. Os gêneros escolares: das práticas de linguagem aos objetos de ensino. In: SCHNEUWLY, B.; DOLZ, J. Gêneros orais e escritos na escola. Campinas, SP: Mercado de Letras, 2004. p. 71-91.

SOARES, D. A Globalização numa perspectiva sociocibernética, In:

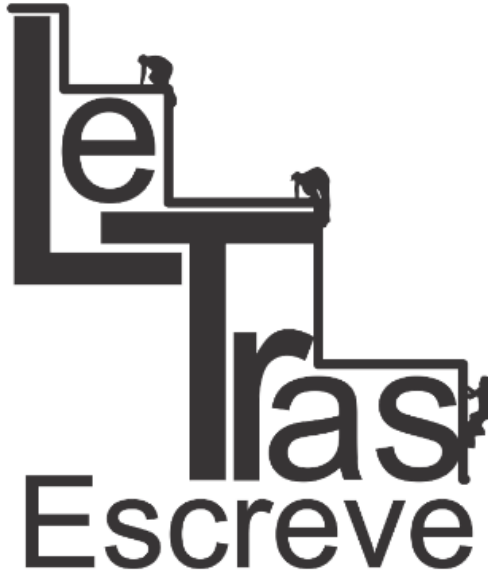

(ISSN 2238-8060)
Revista Contracampo, no1. Mestrado da UFF, jul/dez/1997.

SILVEIRA, M. M. da. Educação e inclusão digital para idosos um curso bem sucedido. Rev. Ciênc. Ext. v.5, n.2, p.4-14, 2009. Sternberg RJ. Psicologia cognitiva. 4aㅡ ed. Trad. Osório MRB. Porto Alegre: Artmed; 2008.

VALENTE, J. A. Diferentes usos do Computador na Educação, in Valente, J. A. (org.), Computadores e Conhecimento: Repensando a Educação. Campinas, SP, Gráfica Central da Unicamp, 1993.

WORLD HEALTH ORGANIZATION. (2005). Envelhecimento ativo: uma política de saúde. Brasília: Organização Pan-Americana da Saúde.

\section{Referência CEJA Donaninha Arruda}

Regimento interno (Versão - 2015);

Projeto Político Pedagógico - 2016;

Plano anual de atividades - 201

Recebido em 25/05/2017

Aceito em 24/09/2017

https://periodicos.unifap.br/index.php/letras

Macapá, v. 7, n. 4, 2o semestre, 2017 